\title{
Editorial
}

\section{No reserved communication lanes for high energy}

The American particle physics community is in jeopardy and may end up drowning in a boundless sea trying to grasp at non-existing funds, dragging US physics and science as a whole to the bottom. This is a price the most powerful and high-tech country of the world cannot afford, as warned by the editors of a report published in late April by the National Academy of Sciences ${ }^{1}$. Behind so much alarm is the International Linear Collider (ILC) - a large particle accelerator facility which, according to the report, should be built on American territory, if research on the elementary constituents of nature is to survive in the United States. The ILC will probably cost a total of five hundred million dollars in the first five years, whereas billions will have to be invested in the subsequent seven years. Hardly impressive, however, if compared with the Superconducting Super Collider (SSC), the biggest and costliest machine ever conceived in the history of science. Devised to describe the first instants of the universe, as many will recall, the SSC project was severely hampered by political and bureaucratic plots in 1993, when the Clinton administration decided to halt work on the accelerator, after ten years and approximately two billion dollars already spent.

The ruins of the greatest failure in American particle physics consist in an abandoned tunnel - some twelve miles long - in the vicinity of Waxahachie, Texas. The project envisaged excavations for many other miles but sadly ran out of money. The last estimate before the cancellation ordered by the administration reported a sum of eight billion dollars needed to complete the building work. Hence, although the present requests seem insignificant by comparison, cost estimates reveal that this might be the last chance for American researchers. Referring to it as a fight for survival is an overstatement, yet American high-energy physicists may now have become aware that over the years they have become an increasingly marginal group within the American scientific community. Add on top of that their rivalry and psychological subjection towards their European colleagues at CERN (European Organization for Nuclear Research) in Geneva. And yet, this is not enough to account for this "now or never" campaign.

When the United States Congress decided to pull the plug on the SSC project, various causes were identified for the demise. Among the most convincing reasons are the lack of precise cost assessments, poor project management by physicists and officials working at the Department of Energy, conflicts within the community itself, the end of the Cold War and, as a result, of the obsession to demonstrate the US supremacy over the Soviet Union, as well as a certain reluctance by President Clinton to pursue a project launched under the aegis of his Republican opponents ${ }^{2,3}$. In the turmoil of recriminations and evaluations on the proportional weight each reason had in that fiasco, a widely held view is that scientists in first place have proved to be unable to explain in straightforward terms why so many public funds should be spent to build a facility to make elementary particles collide. A more subtle interpretation of the issue is that particle physicists have turned out to be unable - or unwilling - to expand their sphere of influence in the attempt to persuade other scientists and policymakers that the project was necessary ${ }^{4}$. Although they provided scientific claims entirely beyond criticism, the researchers involved in the SSC failed to provide what was defined as a "socially robust" science". Following this interpretation, the ground on which the American physicists have lost their battle is public communication, both in terms of the interaction with other scientific communities (biologists, in the specific case of the SSC) and with other relevant groups involved in the negotiations for the project's development. American particle physicists have underestimated the crucial role played by public communication in guiding the development of their own research activity. Their relation with society was affected by a stereotypical scheme according to which scientists communicate with the so-called non-experts only after relevant decisions are made within the small academic circle they belong to. The story of the SSC showed this is not the case. Have they learned their lesson? Was that failure fully understood? These are questions posed by the journal Science some time ago, and the conclusion was that many aspects of the new ILC enterprise remain unclear ${ }^{6}$. Apparently a step forward was taken in the involvement of scientists belonging to other areas other than particle physics in the support to the ILC. The document by the National Academy of Sciences was signed by important personalities such as the 
economist Harold T. Shapiro and the Nobel Prize biologist Harold Varmus. We believe, however, that the people presently in charge of the project would be greatly mistaken if they considered the SSC as an exception - a short circuit stemming from historical circumstances. Like it or not, public communication carried out according to rules, methods and expectations diverging from those in force within their hidden small circle is an essential requirement in the work of contemporary scientists. It is something they must come to terms with. This holds particularly true - especially today - for particle physicists.

Nico Pitrelli

Translated by Massimo Caregnato

\section{Notes and references}

1 Committee on Elementary Particle Physics in the 21st Century - National Research Council, Revealing the Hidden Nature of Space and Time: Charting the Course for Elementary Particle Physics, The National Academies Press, Washington, 2006.

2 L. Hoddeson and A. W. Kolb, “The Superconducting Super Collider's Frontier Outpost, 1983-1988”, Minerva, 38 (3), 2000 : pp. 271-310.

3 M. Riordan, "The Demise of the Superconducting Super Collider", Physics in Perspective, 2(4), 2000: pp. 411-425.

${ }_{5}^{4}$ M. Gibbons, "Science's New Social Contract With Society”,. Nature, 402 (suppl.), 1999: C81-84.

5 M. Gibbons, C81-84.

6 "Lots of Reasons, But Few Lessons", Science, 302, 2003: pp. 38-40. 